\title{
FORMAÇÃO DO SISTEMA AGRÁRIO NA REGIÃO DO PARANÁ TRADICIONAL: UM ESTUDO DE CASO DA COMUNIDADE RURAL LINHA CRICIUMAL EM CÂNDIDO DE ABREU
}

\author{
Juliano Strachulski ${ }^{1}$ \\ Nicolas Floriani ${ }^{2}$
}

\section{Resumo}

O presente estudo busca, em um primeiro momento, retratar a história da configuração socioespacial do sistema agrário do Paraná Tradicional, e como objetivo central, num segundo momento, buscase caracterizar e analisar o sistema agrário da comunidade rural Linha Criciumal no município de Cândido de Abreu. O contato entre o imigrante e o caboclo nesta região vai acabar proporcionando novos elementos sociais ao sistema agrário em formação, a partir do surgimento da lógica produtiva camponesa que emerge deste contato. A metodologia contou com uma revisão de literatura e realização de trabalhos de campo. De início, visou-se uma aproximação com a comunidade, e através de técnicas de pesquisa participativa procedeu-se a realização de entrevistas de caráter aberto, semi-estruturado e não estruturado. Desta forma, foi possível caracterizar o sistema agrário da comunidade Linha Criciumal como híbrido, pois possui tanto características dos modelos agrícolas europeus como do caboclo além da incorporação de elementos da modernização da agricultura. Hoje (século XXI) se observa paisagens produtivas diferentes daquelas de 40 anos atrás, onde

${ }^{1}$ Graduado em Geografia Bacharelado (UEPG). Mestrado em Gestão do Território (UEPG). Doutorado em andamento em Geografia (UEPG). Email: julianomundogeo@gmail.com

${ }^{2}$ Graduado em Agronomia (UFPR). Mestrado em Ciências do Solo (UFPR). Doutorado em Meio Ambiente e Desenvolvimento (UFPR). Prof. Adjunto da Universidade Estadual de Ponta Grossa (UEPG). Prof. Permanente do Programa de Pós-graduação em Geografia (UEPG). E-mail: florianico@gmail.com 
havia relações sociais mais equânimes com uma organização social mais coesa, e maior dependência às limitações do meio físico.

Palavras-chave: Colonização, hibridismo, modelos agrícolas, sistema agrário, paisagem.

\title{
FORMATION OF AGRARIAN SYSTEM IN THE REGION OF PARANÁ TRADITIONAL: A CASE STUDY OF THE RURAL COMMUNITY LINHA CRICIUMAL IN CANDIDO DE ABREU
}

\begin{abstract}
The present study seeks, in a first moment, portray the history of socio-spatial configuration of agrarian system of Paraná Traditional, and as central objective, at a second moment, is sought to characterize and analyze the agrarian system of the rural community Linha Criciumal in city of Cândido de Abreu. Contact between immigrant and Caboclo in this region will end up providing new social elements to the agrarian System in formation, from the appearance of the productive peasant logic which is created from this contact. The methodology included literature review and fieldwork. First, it was sought approximation to the community, and through participatory reasearch techniques interviews of open, semi-structured and unstructured character were carried out. Thus, it was possible to characterize the agrarian System of Linha Criciumal as hybrid, as it has characteristics from both European agricultural models and Caboclo, as well as the incorporation of elements of the modernization of agriculture. Today (XXI century) we observe productive landscapes, different from those of 40 years ago, where there were more equitable social relations with a more cohesive social organization and greater dependence on the limitations of the physical environment.
\end{abstract}

Key-words: Colonization, hybridism, agricultural models, agrarian System, landscape. 


\section{INTRODUÇÃO}

Em consequência das fases históricas que condicionaram a colonização do território paranaense, segundo Wachowicz (1995), o estado do Paraná passou por três grandes períodos de ocupação e povoamento, que caracterizaram três diferentes regiões históricoculturais ligadas a esta ocupação, sendo elas o Paraná Tradicional, o Norte e o Sudoeste (figura 1).

\section{Figura 1 - Regiões histórico-culturais do Paraná}

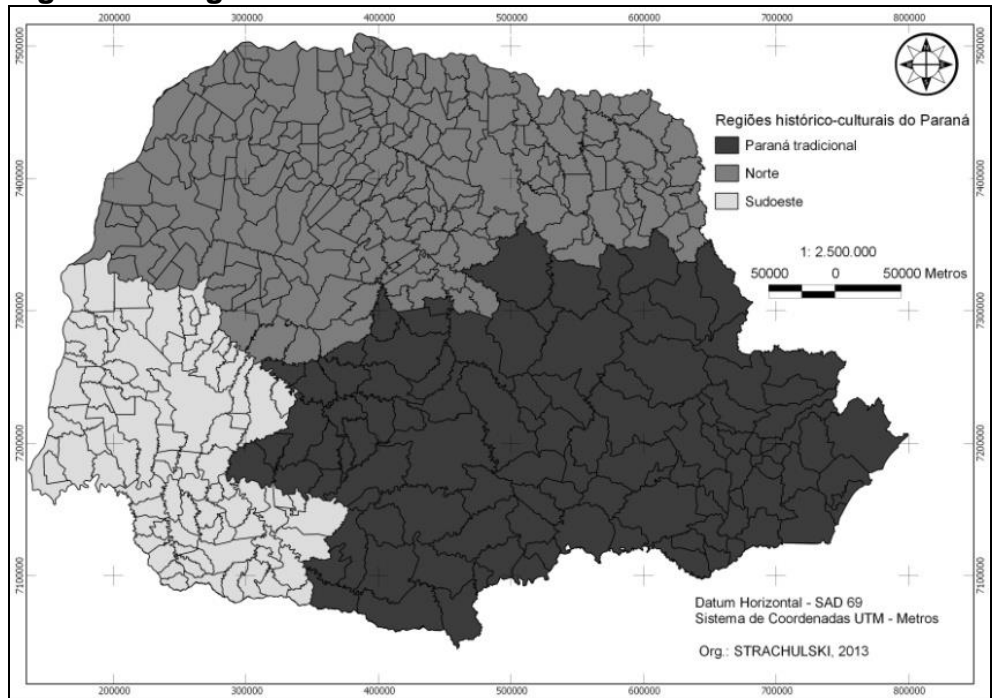

Fonte: Adaptado de MACHADO, 1963.

Neste sentido, compreende-se que o Paraná Tradicional foi a primeira região a passar pelo processo de ocupação e povoamento. Tal região tem sua história de formação socioespacial iniciada no século XVII, devido ao início do ciclo do ouro em Paranaguá, Curitiba, ente outras cidades. Já no século XVIII sua história ganha novos componentes com o surgimento das tropas e a atividade pecuarista, proporcionando a ocupação das áreas de 
campo (Wachowicz, 1995); no século XIX, com a chegada dos imigrantes e as atividades de extração da erva-mate e da madeira.

Para tanto, esta análise se inicia a partir do recorte histórico referente à chegada dos imigrantes no final do século XIX, no qual figura no espaço regional uma estrutura fundiária marcada pela presença tanto de grandes fazendas, como de pequenas propriedades familiares, e a relação desta com o campo e a Floresta Ombrófila Mista (FOM). Tal período é marcado pelo contato entre a cultura cabocla e do imigrante, proporcionando novos elementos sociais ao sistema agrário em formação a partir do surgimento da lógica produtiva camponesa que emerge deste contato.

Estes elementos ajudam a entender a formação do sistema agrário regional a partir da leitura das mudanças circunstanciais da agricultura, levando-se em conta os macroprocessos socioeconômicos em escala internacional e nacional e sua influência nos microprocessos socioterritoriais na escala regional e local.

Compreendendo estas transformações, a leitura dos processos socioespaciais marcados na paisagem possibilitam uma compreensão inicial do sistema agrário (GARCIA FILHO, 1999; MAZOYER; ROUDART, 2010), permitindo entender ao longo do tempo as alterações das relações sociais e das técnicas e práticas agrícolas adotadas pelos produtores rurais.

A compreensão do sistema agrário, assim, é importante para se poder entender e caracterizar as mudanças de conjuntura da agricultura regional e suas transformações históricas e geográficas dentro do processo de estabelecimento das práticas agrícolas (MAZOYR, 1987 apud GARCIA FILHO, 1999).

Sistema agrário pode ser definido como uma concepção teórica de uma forma de agricultura, historicamente instituído e geograficamente localizado, entendido como um modo de exploração do meio que possui um sistema de forças de produção e um sistema técnico adaptado às condições pedobioclimáticas locais e que, além disso, responde às condições sociais do momento (MAZOYER; ROUDART, 2001).

A partir de uma abordagem complexa das relações entre sociedade e natureza, o enfoque sistêmico, a partir do conceito de sistema agrário, mostra-se pertinente por estabelecer pontos de inteligibilidade entre as dimensões sociais e ecológicas.

Percebe-se, assim, que a teoria de sistemas possibilita interpretar a realidade de forma holística, de acordo com diferentes 
abordagens científicas do espaço rural. Entretanto, estas abordagens não devem ser consideradas complexas na interpretação da realidade, pois o recorte do sistema apresenta a possibilidade de ser utilizado em qualquer nível de escala e segundo o escopo do pesquisador, podendo ser: "geossistema/ecossistema/sistema de cultivos/sistema planta-solo-animais/sistema fisiológico" (FLORIANI; FLORIANI, 2010, p. 16).

Nesta mesma lógica aparece a noção de agroecossistema que também pressupõe a entidade espacial (paisagem) e exige, assim, a complexidade sócio-antropológica como elemento de sua estrutura e organização:

(...) Nestas unidades geográficas e socioculturais [as paisagens onde são desenvovidos os agroecossistemas], os ciclos minerais, as transformações energéticas, os processos biológicos e as relações sócioeconômicas, constituem o lócus onde se pode buscar uma análise sistêmica e holística do conjunto destas relações e transformações (CAPORAL e COSTABEBER, 2002, p. 14).

Assim, em relação ao sistema agrário local, a leitura da paisagem rural e a interpretação das memórias dos antigos agricultores possibilitam entender os processos socioeconômicos envolvidos na transformação desta.

Segundo Sanches e Machado (2009), em 1971 a Unesco considerou a paisagem como a estrutura do ecossistema, e o Conselho Europeu compreendeu que, sob o olhar humano, o meio natural, moldado pelos fatores sociais e econômicos torna-se paisagem.

A paisagem, neste sentido, é importante que seja pensada como [...] "um conjunto de formas que, num dado momento, exprime as heranças que representam as sucessivas relações localizadas entre homem e natureza [...]" (SANTOS 2006, p. 66). Assim, ela torna-se resultado da "interação entre elementos físicos, biológicos e antrópicos" (BERTRAND, 1971; TRICART, 1979 apud VENTURI, 2008, p. 51).

A partir do acima dissertado, esta pesquisa busca, em um primeiro momento retratar a história da configuração socioespacial do sistema agrário do Paraná Tradicional, e como objetivo central, 
num segundo momento, busca-se caracterizar e analisar o sistema agrário da comunidade rural Linha Criciumal, no município de Cândido de Abreu.

\section{MÉTODOS E TÉCNICAS}

O presente texto se divide em duas partes, sendo que na primeira é retratada a formação do sistema agrário regional e na segunda parte se busca caracterizar e analisar o sistema agrário da comunidade Linha Crciumal.

Assim, num primeiro momento, buscou-se mostrar como ocorreu a formação do sistema agrário da região Paraná Tradicional, retratando a relação da população que se formava com os fatores socioeconômicos e ambientais, apresentando as características dos modelos agrícolas do imigrante e o do caboclo.

Num segundo momento, foram efetuados trabalhos de campo na comunidade rural de Linha Criciumal, com observações referentes à prática agrícola, direcionadas aos equipamentos utilizados, as relações de trabalho estabelecidas entre os agricultores, os cultivos plantados, as formas de preparo da terra, a possibilidade de integração entre os subsistemas agrários e a disposição geral dos elementos na paisagem. Tal comunidade conta com uma população de descendentes de eslavos (poloneses e ucranianos) e caboclos.

De início, buscou-se uma aproximação com a comunidade. Para tanto, utilizou-se como elemento da pesquisa participativa a técnica de história de vida, visando apresentar elementos do histórico da comunidade. A técnica de história de vida ou história oral busca através do diálogo, por meio de uma entrevista, compreender a história de formação de um grupo, contada por uma ou mais pessoas (ALBUQUERQUE et al., 2010).

Na sequência, um teste piloto foi realizado. Tal instrumento é aplicado de forma preliminar à entrevista definitiva, abrangendo uma pequena amostra de participantes, servindo como norteador para a realização da pesquisa propriamente dita, possibilitando correções de questionário, amostra, e assim por diante, buscando a validação da entrevista (ALBUQUERQUE et al., 2010). Destarte, através de técnicas de pesquisa participativa como a elaboração de entrevistas de caráter aberto, semi-estruturado e não estruturado 
(VERDEJO, 2006; ALBUQUERQUE et al., 2010), visou-se caracterizar o sistema agrário da comunidade.

$\mathrm{Na}$ comunidade Linha Criciumal há em torno de 150 pessoas residindo, sendo distribuídas em 35 famílias, deste contingente se constatou que 17 famílias trabalham com atividade agrícola, sendo este o critério nodal para a escolha dos entrevistados. Das 17 famílias que trabalham com atividade agrícola foi possível realizar a entrevista com 11 famílias, pois os outros potenciais informantes não foram encontrados nos dias em que se realizou o trabalho de campo e/ou não aceitaram participar. As 11 famílias que participaram da pesquisa representaram um esforço amostral de quase $32 \%$ do total de 35 famílias.

Deste modo, os 11 informantes, sendo o (a) chefe-defamília e seu cônjuge e/ou parceiro de trabalho, foram eleitos de acordo aos seguintes critérios: posse legal da terra, agricultura como atividade principal, tempo de residência na comunidade (mínimo de 20 anos), vínculo matrimonial (casado (a) e relações de trabalho (troca de dias, parceria, arrendamento, reunida, entre outros.).

As entrevistas foram efetuadas nas residências dos moradores, sendo que apenas em três ocasiões as mulheres não estavam presentes. Os trabalhos de campo ocorreram no mês de outubro de 2012.

Quanto à naturalidade dos entrevistados, apenas três pessoas nasceram fora da comunidade, sendo que o tempo médio de residência destes na comunidade é de 30 anos. Na medida do possível, buscou-se conversar com as pessoas mais velhas da comunidade, por terem uma maior vivência no trabalho agrícola, e por terem condições de falar do passado. A média de idade dos entrevistados chegou a 50 anos, com intervalo entre 27 a 65 anos.

A compreensão do sistema agrário local passou pela elaboração do calendário de cultivos, itinerário técnico e histórico de cultivos (GARCIA FILHO, 1999), podendo-se inferir acerca das práticas produtivas por eles empregadas na lavoura, resumindo descritivamente a relação entre as etapas, as técnicas, os instrumentos e recursos disponibilizados na produção do componente central do sistema de produção: a cultura do feijão.

Já o conceito de paisagem, não utilizado como tal, mas enquanto um dos procedimentos da metodologia do diagnóstico de sistemas agrários (GARCIA FILHO, 1999; MAZOYER; ROUDART, 2010), permitiu indicar os elementos que entram em jogo no sistema 
produtivo local através da leitura das formas contidas nesta, possibilitando entender o sistema produtivo e agrário.

Assim, a compreensão, de como é organizado o sistema agrário praticado pelos agricultores da comunidade Linha Criciumal passa por um resgate histórico mostrando a estrutura agrária da região Paraná Tradicional, o contato entre imigrantes e caboclos e seus modelos agrícolas.

\section{A ESTRUTURA AGRÁRIA E O CONTATO ENTRE IMIGRANTES E CABOCLOS NO PARANÁ TRADICIONAL: A FORMAÇÃO DO SISTEMA AGRÁRIO REGIONAL}

Em relação ao processo de formação da região Paraná Tradicional, o foco deste trabalho incide sobre o município de Cândido de Abreu, que começa a ser modelado com a chegada dos imigrantes no final do século XIX.

No final do século XIX figura no espaço regional uma estrutura fundiária marcada pela presença tanto de grandes fazendas, cujos produtos eram voltados para a exportação, como de pequenas propriedades, que cultivavam produtos de consumo familiar, além de fornecer produtos e mão-de-obra, prestando auxílio à agricultura comercial (HAURESCO; MOTECA, 2008). Outro fato que deve ser levado em consideração é a relação desta estrutura fundiária (fazendas e propriedades familiares) com o campo e a Floresta Ombrófila Mista (FOM).

Este período também é marcado pelo contato entre a cultura cabocla e do imigrante, proporcionando novos elementos sociais ao sistema agrário a partir do surgimento da lógica produtiva camponesa que emerge deste contato.

A lógica produtiva camponesa é expressa por um modo de vida vinculado a vida comunitária (leis consuetudinárias de organização social), mão-de-obra familiar, práticas agrícolas de subsistência dependentes das demandas familiares, o apego ao território, tênue ligação com o mercado (dependente do excedente da produção), dependência dos ciclos naturais, organização do trabalho ligada as práticas de reciprocidade, incipiente grau de mecanização, resultando em baixa rentabilidade. (GOMES, 2009). 
Neste sentido, a lógica produtiva camponesa, em sua origem, visa à reprodução de seu modo de vida e não o lucro. Paulino (2003, p. 10) complementa,

"O campesinato (ou lógica produtiva camponesa) procura na terra, muito mais que a renda, mas a concretização de um modo de vida pautado na autonomia do trabalho e na reprodução social delimitada pelos profundos vínculos familiares e comunitários".

Woortman (2009), por sua vez, assevera que o perfil da família (idade, gênero, ente outros quesitos), bem como suas necessidades são alguns dos fatores essenciais de que se constitui a lógica produtiva camponesa. Deste modo, conseguem compreender suas limitações e potencialidades ligadas à produção para autoconsumo e/ou venda, sabendo o que podem produzir para a manutenção de seu modo de vida.

No Paraná Tradicional a história da estrutura agrária deriva, então, da relação da sociedade em formação com os ecossistemas e organização fundiária, isto é, latifundiários (lógica mercadológica) e minifundiários (lógica produtiva camponesa). É a história da propagação ora conflitiva ora consuetudinária dos pequenos estabelecimentos rurais, em territórios onde dominavam os latifúndios. Essa história vem ao encontro da Emancipação Política do Paraná em 1853, cujo eixo motor e principal responsável foi o ciclo da exportação da erva-mate com base na exploração da FOM, pois anteriormente predominavam os latifúndios voltados à criação de gado.

Assim, havia duas formas predominantes de organização fundiária, aquela das pequenas propriedades agrícolas associadas aos recursos contidos na FOM e aquela das grandes fazendas, que estava associada à exploração dos campos com a atividade pecuária.

Desta forma, têm-se os caboclos, e os imigrantes posteriormente, morando nas áreas de FOM, sobrevivendo de uma agricultura de subsistência que quando produzia excedentes de produtos primários, destinava-os à venda para abastecer as fazendas próximas e áreas urbanas, além da atividade de extração da erva-mate (venda) e madeira (lenha e construção). Nestas áreas havia um razoável contingente de famílias. 
Por outro lado, as fazendas não produziam nada além de gado bovino para a venda. Eram carentes em produtos primários e diferentemente das pequenas propriedades dos caboclos, não proporcionavam uma ocupação efetiva da terra, pois seus donos não estavam ligados àquelas terras e sim as criações de gado, que por sua vez recolhia mão-de-obra muito inferior a das propriedades familiares (PADIS, 1981).

Segundo Wachowicz (1995), no início do século XIX, o território paranaense era uma região pouco povoada, um sertão bruto. Haviam poucos povoados, como Guarapuava, Lapa, Castro, entre outros. A falta de mão-de-obra escrava agravava a situação e, conhecedora dela as autoridades provincianas "alimentaram a esperança de que a introdução de novos contingentes populacionais imigrados proporcionaria condições de mudança e progresso agrário para a Província" (BALHANA, 1996, p. 47).

No segundo quartel do século XIX aparecem os primeiros imigrantes, que passam a ocupar as terras de forma espontânea. Já na segunda metade do século XIX, segundo Serra (1992), o governo assume projetos de colonização, visando acabar com a forma irregular como a terra vinha sendo ocupada, ou seja, de forma espontânea. Outro problema enfrentado era o baixo incentivo à população paranaense majoritariamente rural em relação à atividade agrícola voltada ao mercado interno, além da pouca mão-de-obra disponível devido à proibição da importação de escravos a partir de 1850.

Assim, visando solucionar esses problemas e de quebra promover um "clareamento" da população se tem a vinda intensificada dos imigrantes europeus, com a formação de colônias normalmente localizadas na FOM (WACHOWICZ, 1995).

$\mathrm{Na}$ segunda metade do século XIX, a região do Paraná Tradicional compreendida pelos campos estava rodeada de estabelecimentos de elevadas dimensões territoriais, devido às fazendas de gado e uma crescente cobiça pelas reservas de pinheiros das matas de araucária (HAURESCO; MOTECA, 2008). Enquanto que, com a vinda dos imigrantes ocorre um expressivo aumento no número de pequenas propriedades rurais nas matas de araucária.

O desenvolvimento da atividade madeireira e a continuidade da pecuária de caráter extensivo, segundo a concepção de Padis (1981), não proporcionaram ocupação mais efetiva da terra, pois as 
duas atividades tinham como princípio somente a exploração, sendo que os proprietários das terras não possuíam vinculo com estas, não Ihes interessando investir nelas.

Contudo, deve-se destacar que também há outras formas de exploração como das comunidades tradicionais que não investem nas terras que trabalham, mas estão intimamente ligados a elas, como os faxinalenses, os quilombolas, os indígenas, dentre outras comunidades. A falta de investimento, no caso de tais comunidades, indica que sua lógica não é a geração de riqueza, mas sim proporcionar o desenvolvimento de sua forma de vida.

Como de início a colonização visava preencher os espaços despovoados do Paraná, eram criadas colônias em áreas interioranas, que ficavam muito distantes das áreas urbanas. Tal distanciamento provocava o isolamento geográfico, o que dificultava o trabalho agrícola, pois a comercialização da produção ficava comprometida, havendo somente carreiros e mata fechada.

As colônias implantadas expressavam uma relação de equilíbrio entre o colono e o meio natural, pois os instrumentos que havia para o trabalho agrícola eram bastante rudimentares e com baixa capacidade de intervenção neste meio. De modo que, as áreas em que foram implantadas as colônias não eram geograficamente ideais ao desenvolvimento agrícola, pois, além da mata (FOM) fechada, possuíam grandes declividades e relevo forte ondulado, apresentando-se como um agravante ao desenvolvimento das colônias. Estas, em sua maioria, mantiveram por grande período uma economia de subsistência e não contribuíram como esperavam os idealistas da colonização, para alterar os hábitos e costumes da sociedade tradicional paranaense (HAURESCO; MOTECA, 2008).

O meio natural era elemento de grande empecilho ao desenvolvimento agrícola, segundo os moldes produtivos europeus, de modo que os colonos pouco podiam fazer para superar suas dificuldades. Sua interferência no meio físico se dava de maneira lenta e gradual, devido ao baixo desenvolvimento no tocante a equipamentos agrícolas. Segundo Domingues (1986, p. 116, grifo nosso),

Esta fase de desenvolvimento tecnológico não permitia facilmente anular os efeitos dos acidentes naturais de maneira a permitir uma maior fluidez na circulação de pessoas, mercadorias e informações, nem possibilitar 
um desenvolvimento econômico $\quad \mathrm{e}$
sociocultural marcante.

De início, os imigrantes europeus buscaram implantar seus modelos agrícolas nas regiões de mata com araucária, onde se instalaram. Contudo, deve-se ressaltar que cada grupo buscou se adaptar a sua realidade, necessidades e capacidade de transformação do meio. Assim, o imigrante acaba trazendo consigo um conjunto de características de seus países de origem, "onde muitas continuaram em solo paranaense e outras foram esquecidas ou readaptadas as condições encontradas pelo imigrante na área que foi estabelecido" (HAỦRESKO e MOTEKA, 2008 p 15). Portanto, compreende-se que os diversos grupos de imigrantes que adentraram ao território paranaense adotaram modelos agrícolas distintos (WAIBEL, 1949 apud SCHNEIDER, 2002).

Assim, alguns grupos de imigrantes passaram a adotar 0 modelo agrícola caboclo da roçada com queimada da vegetação, pois as condições ecológicas que os agricultores imigrantes encontraram principalmente na região Sul do Brasil eram distintas daquelas da Europa, uma vez que os solos de florestas eram mais ricos em nutrientes, proporcionando várias colheitas sem a necessidade de adubos e sem a rotação de culturas (MERTZ, 2004).

Neste modelo agrícola, os cultivos predominantes eram também alguns dos que os caboclos cultivavam, além de seus habituais, trigo, centeio e arroz. Este colono não adubava o solo. Os principais instrumentos agrícolas utilizados eram o machado, a enxada, e a foice, sendo que as sementes eram plantadas à mão (WAIBEL 1949 apud SCHNEIDER, 2002). Seu meio de transporte da produção: o carroção eslavo, desconhecido até então, tornou-se o meio de transporte mais eficiente nessas regiões por sua maior capacidade de transporte de cargas.

Num outro modelo, havia os mesmos elementos técnicoprodutivos do anterior, contudo, neste se tem a integração da lavoura com a pecuária, pois além de contribuir para a renovação da fertilidade a criação animal também disponibilizava a força para tração, permitindo o uso do arado para revolver o solo (WAIBEL 1949 apud SCHNEIDER, 2002; MAZOYER; ROUDART, 2010). Neste modelo os colonos começavam a praticar o pousio em suas propriedades, que consistia em uma rotação de curta duração com 15 a 21 meses de pousio, seguida de quatro a nove meses de cultivo (MAZOYER; ROUDART, 2010). 
Havia mais um modelo agrícola, que era o sistema de rotação de culturas (sem pousio) combinada com a criação de gado, e plantio de forrageiras temporárias como nabo e aveia (WAIBEL 1949 apud SCHNEIDER, 2002). Ao invés das rotações de terras haviam as rotações de culturas (três, quatro ou seis anos), que compreendiam a aragem e a adubação dos campos com o uso de no mínimo um ou dois cavalos para a tração, e uso de equipamentos mais pesados como 0 arado reversor e a grade (MAZOYER; ROUDART, 2010).

Concomitantemente a estes modelos agrícolas, era consolidado um modelo baseado na roçada e queimada. Tal modelo caboclo versava sobre a roçada de vegetação arbórea, compreendida como capoeira, com sua posterior queimada, e quando a queimada deixava sobras de vegetação se procedia ao "encoivaramento" ${ }^{3}$ (VALVERDE, 1968). Além desta prática, o modelo agrícola caboclo se baseava em uma rotação de áreas e cultivos. Após o curto período de cultivo, a parcela era abandonada a um pousio arbóreo de longa duração, para formar uma rotação, antes de ser novamente desmatada e apta ao cultivo, o qual poderia durar de dez a várias dezenas de anos. Assim, a cada ano, esse cultivo mudaria de lugar e da mesma forma os cultivos secundários que Ihes sucederiam também se deslocariam (MAZOYER; ROUDART, 2010).

Não havia o revolvimento do solo, e a reprodução da fertilidade se dava pelo crescimento da vegetação, a partir de uma formação secundária (capoeira) em área queimada abandonada. Seus cultivos principais eram o milho, o feijão, a mandioca e a abóbora. Seus principais instrumentos de trabalho eram a cavadeira, enxada ou enxadão, machado foice e facão de mato. Já a criação de animais (porcos) era a solta, sendo que estes também possuíam livre acesso às áreas de roça, contudo, não proporcionavam força ao trabalho agrícola nem produção de adubo (VALVERDE, 1968).

Essa agricultura itinerante caracteriza a atividade agrícola em várias regiões do Brasil e em específico algumas regiões do Estado do Paraná, como o Terceiro Planalto, excluindo o Norte, e o Segundo Planalto (VALVERDE, 1968).

\footnotetext{
${ }^{3}$ As coivaras consistem em "fogueiras espalhadas num roçado, feitas com galhos e ramos não consumidos pela queimada". (VALVERDE, 1968, p. 227).
} 
Assim, a partir da necessidade da troca de produtos agrícolas por outros bens os imigrantes tiveram que entrar em contato com a sociedade, e ao invés de os nativos adquirirem os hábitos dos imigrantes, estes tiveram que aprender os costumes locais, num primeiro momento, pois precisaram se relacionar com outros grupos étnicos para aprender sobre o meio ambiente e sobrevivência nas novas colônias.

Deste modo, os imigrantes aos poucos foram absorvendo a forma de agricultura dos caboclos, passando a plantar cultivos praticados por estes como o milho, o feijão e a mandioca e realizar a extração da erva-mate e madeira. Porém, os colonos também exerceram certa influência sobre os caboclos no tocante a técnicas produtivas e praticas sociais.

As peculiaridades ecológicas e socioeconômicas a que foram aqui submetidos os imigrantes, mais o contato e miscigenação com o caboclo, proporcionaram novos elementos sociais ao sistema agrário em formação, a partir do surgimento da lógica produtiva camponesa que emerge deste contato.

No início do século $X X$, portanto, começa a se formar o sistema agrário regional, a partir das mudanças circunstanciais da agricultura, sendo, portanto, o resultado tanto de macroprocessos socioeconômicos em escala internacional e nacional (difícil acesso a terra na Europa, crises econômicas, imigração), como de microprocessos socioterritoriais na escala regional e local (alteração da estrutura agrária, novos modelos agrícolas, contato entre imigrante e caboclo).

Outro elemento que vai proporcionar alterações ao sistema agrário local em formação, e a paisagem que resulta da implantação destes, algumas décadas mais à frente, é a modernização da agricultura, que chega com força a partir da década de 1960-1969 (TEIXEIRA, 2005).

Deste momento em diante os sistemas agrários, tanto regionais, nacionais e até em nível mundial, sofreram cada vez mais alterações sugeridas pelos grupos humanos e cada vez menos alterações impostas pelo meio físico, pois na medida em que novas invenções ganhavam espaço na agricultura, esta acabava se modernizando ${ }^{4}$. $O$ incremento de novas práticas, insumos e

\footnotetext{
${ }^{4}$ A modernização da agricultura pode ser considerada como o emprego e uso intensivo do arcabouço técnico-instrumental e químico-genético, os quais possibilitam um maior rendimento no processo produtivo (FAGUNDES et al., 2010). Sendo que neste processo
} 
implementos acabavam causando a alteração destes sistemas, tendo em vista que as mudanças são perceptíveis e denotam uma alteração da relação do homem com o meio, pois, com novas técnicas e equipamentos modernos, o produtor passa a diminuir sua dependência em relação aos recursos naturais.

\section{COMUNIDADE RURAL LINHA CRICIUMAL: HIBRIDAÇÃO DE IDEÓTIPOS AGRÍCOLAS}

Resultado do processo de colonização, a comunidade de Linha Criciumal ${ }^{5}$ é uma das muitas da região que tiveram sua origem a partir da fundação da Colônia Thereza em 1847, sob os auspícios do médico e naturalista francês João Maurício Faivre, na região do rio Ivaí, onde no século XXI se encontra, dentre outros, o município de Cândido de Abreu.

Com o grande contingente populacional que chegava à colônia, esta já não possuía condições de abrigar mais imigrantes que vinham do leste europeu e de outras regiões do Paraná, de modo que passaram a se estabelecer no entorno da colônia Thereza, formando novas comunidades.

A presente comunidade pertence ao município de Cândido de Abreu (figura 2), que por sua vez pertence à região Território Paraná Centro (IPARDES, 2007). Como o município de Cândido de Abreu fez parte da região Paraná Tradicional seu histórico de formação e ocupação está vinculado às atividades econômicas tradicionais, relacionadas na maioria das vezes a empreendimentos

\footnotetext{
há a transformação de ecossistemas e agroecossistemas em monoculturas, provocando uma erosão genética, acentuando a extinção tanto de espécies animais quanto vegetais (FAGUNDES et al., 2010). O que é corroborado pelos impactos causados a agrobiodiversidade e conhecimentos tradicionais, tendo em vista que "deixam de ser produzidas e utilizadas sementes de variedades adaptadas às condições socioambientais específicas e passam a serem produzidas apenas variedades comerciais" (COELHO-DE-SOUZA, 2010, p. 78). Contudo, vale destacar que tal processo não se restringe somente aos equipamentos e implementos usados, mas também revela um processo de modificação ocorrido no âmago das relações sociais inerentes a produção.

${ }^{5}$ A origem do nome da comunidade deve-se a grande quantidade de uma espécie de taquara denominada de Criciúma (Chusquea sp.) que havia na época em que vieram os primeiros colonos e a forma de ocupação espacial destes, que passaram a se estabelecer ao longo de uma estrada principal formando uma linha de ocupação.
} 
familiares de pequeno porte, correspondendo a $87,3 \%$ da área de estabelecimentos agrícolas do município (IPARDES, 2007).

Tal constatação confirma os dados referentes à formação do município que se constituiu de várias pequenas propriedades de colonos europeus e caboclos, corroborando com o pensamento de Hauresco e Moteca (2008) quando dissertam acerca da formação da região Paraná Tradicional. Além de que, cerca de $70 \%$ da população reside em sua área rural e há mais de 100 anos agricultores vivem em Linha Criciumal.

\section{Figura 2 - Mapa de localização da área de estudo}

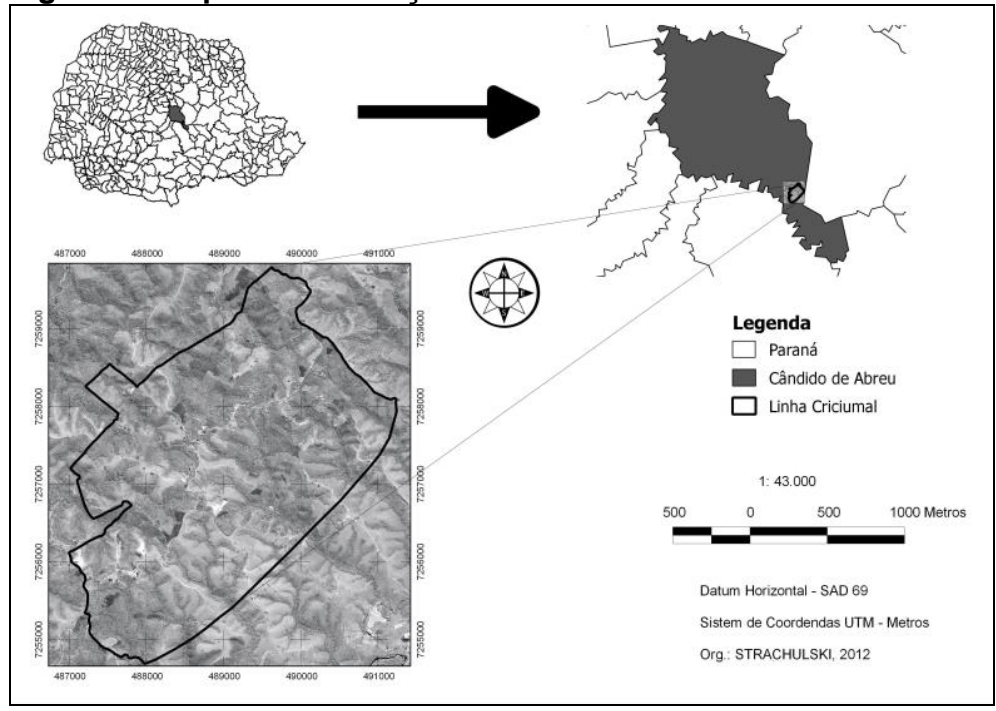

As características físicas apontadas pelo IPARDES (2007) para a área em que se localiza a comunidade Linha Criciumal mostram a presença das maiores declividades do Paraná Centro (sendo estas de 20 a $45 \%$ e acima de $45 \%$ ). Constata-se também a presença de solos com grande potencialidade à degradação, devido à alta probabilidade de riscos à erosão, sendo $50 \%$ dos solos do município de Cândido de Abreu inaptos à agricultura mecanizada (IPARDES, 2007), impedindo a utilização de maquinários, na lavoura, por parte dos agricultores familiares. O processo de 
modernização da agricultura na região, assim, é freado, sendo que a mecanização da lavoura ocorre somente a partir de 1980 (IPARDES, 2007).

Tal particularidade regional fez com que as práticas sociais produtivas das comunidades rurais se adaptassem parcialmente ao processo de modernização do campo, o qual provocou tanto mudanças de técnicas na produção agrícola, como das práticas sociais, representando uma diminuição dos momentos de convívio comum. Desta forma, os saberes e práticas locais ofereceram relativa resistência à modernização e os sistemas culturais souberam se adaptar metamorfoseando (internalizando) em novas práticas materiais e imateriais híbridas. Assim, busca-se a caracterização do sistema agrário da comunidade Linha Criciumal.

$\mathrm{Na}$ área de estudo, percebe-se que existem práticas sociais que reforçam as características tradicionais herdadas de imigrantes e caboclos (sistema social produtivo), como a participação em atividades religiosas, por meio das festas periódicas, além das rodas de chimarrão, reuniões da igreja, partidas de truco, torneios de futebol, festas de ano novo e aniversários.

As práticas produtivas também ajudam a caracterizar um modo de vida tradicional, como os mutirões (esporádicos), a "troca de dias" 6 de serviço na lavoura e o plantio em parceria ou "de as meia" 7 , geralmente estas atividades ocorrem entre parentes e/ou vizinhos mais próximos, mas podem ocorrer também com pessoas de comunidades vizinhas, reforçando a integração entre os moradores.

Por outro lado, no segundo quartel do século $X X$, começam a surgir muitas práticas modernas, o que se comprovou em 2013, como a utilização, pelos agricultores, de adubos, sementes modificadas geneticamente, utilização de forrageiras como a aveia, agrotóxicos e um dos símbolos da agricultura moderna: a bomba costal, além de plantarem feijão e milho em áreas mais planas, com plantadeiras motomecanizadas e debulharem o feijão e 0 milho através de maquinário.

\footnotetext{
${ }^{6}$ É quando ocorre a troca de dias de trabalho entre os vizinhos, ou seja, quando um ajuda no trabalho do outro, prática comum em épocas de colheita, evitando a contratação de empregados e reforçando o laço de solidariedade e de vizinhança.

7 É uma relação de trabalho que se estabelece quando um agricultor oferece a terra a seu vizinho e este entra com o trabalho, ao final da colheita os lucros são divididos ao meio, podendo ser em números de sacas de determinado cultivo ou em dinheiro.
} 
Contudo, o milho e o feijão ainda são puxados nas costas de cavalos ou do próprio produtor até uma área mais apropriada para que possa ser debulhado, por maquinário. Além disso, o feijão quando plantado em pequena quantidade é "malhado no cambal" técnica tradicional. Também realizam capinas com enxada, mesmo que de maneira menos intensa do que antes da modernização da agricultura, além de utilizarem outros instrumentos de agricultura tradicional como o machado, a foice, a cavadeira, e a plantadeira de feijão e milho também chamada de "perna-de-grilo". Todos estes elementos conferem ao seu modo de produção um caráter híbrido no tocante a forma de exploração e gestão dos recursos naturais.

A incorporação de elementos da agricultura moderna como os agrotóxicos e maquinário agrícola tem diminuído a intensidade das relações sociais, pois estes dispensam cada vez mais a mão-deobra, diminuindo as formas de contato social como as trocas de dias de serviço e a prática dos mutirões para arrumar cercas ou ajudar o vizinho na colheita ou capina, que ocorrem somente de forma esporádica. Completando o pensamento, apoia-se em Santos (2001, p. 89, grifo nosso) quando este fala que "[...] a agricultura científica, moderna e globalizada acaba por atribuir aos agricultores inseridos na modernidade à velha condição de servos da gleba [...]", pois, passam a conviver muito mais tempo com ela, deixando de lado as relações sociais.

Compreendendo estas transformações a leitura da paisagem proporcionou entender a mudança ao longo do tempo, das alterações ecológicas, das relações sociais e das técnicas agrícolas adotadas pelos agricultores, de modo que, em 2013 se presencia uma paisagem produtiva diferente daquela de 40 anos atrás, com relações sociais menos intensas e novas técnicas produtivas, ressaltando o tal hibridismo.

Esta hibridação de práticas se reflete na paisagem, pois no final do século XX e início do século XXI ocorre a inserção de alguns sistemas produtivos que não havia há trinta anos, como a bovinocultura, com aumento gradativo do espaço destinado à

\footnotetext{
${ }^{8}$ Malhar feijão no cambal é uma técnica tradicional de extrair a semente do feijão. Tal técnica consiste em esticar uma lona no chão, colocar as vagens de feijão sobre a lona, e em alguns casos faz-se uma parede com a própria lona em volta das vagens do feijão. Em seguida com uma vara bem flexível a pessoa portadora da vara começa a aplicar golpes nas vagens até que soltem as sementes de feijão, que posteriormente são colhidas e ensacadas.
} 
pastagem e diminuindo aquele destinado a agricultura, e a inserção de reflorestamento com exóticas, pinus e eucaliptos, há dez anos. Percebe-se que a modernização da agricultura provocou alterações na paisagem local, intensificadas com o tempo. Tendo em vista que, agricultores locais, anteriormente a modernização da agricultura costumavam plantar uma diversidade maior de cultivos do que se planta no século XXI, denotando um uso diferenciado da paisagem, pois havia arroz, milho, feijão e algodão como cultivos principais, além da pipoca, a batata-doce, o trigo, e outros, e uma área de mata muito maior do que a atual.

A paisagem analisada aqui, portanto, é o resultado da ação antrópica sobre o meio físico, sendo materializada nas formas criadas pela sociedade e passíveis de observação (SAUER, 1998), que aqui se expressam pelos elementos que constituem um sistema agrário e produtivo (GARCIA FILHO, 1999; MAZOYER e ROUDART, 2010). A alteração no uso da paisagem pode ser expressa na seguinte frase de um agricultor: "a gente encheu de eucalipto naquelas terra porque a gente sabe que elas não são boa". Assim, o conhecimento do agricultor, algo construído com a prática, alia-se também ao meio físico como a qualidade do solo, além dos imperativos do mercado, para estabelecer os usos potenciais. Deste modo, a partir da leitura das formas da paisagem é possível entender como se estruturam os sistemas agrários e produtivos.

O hibridismo que se discute e que marca a paisagem não se dá somente entre o moderno e o tradicional, mas também entre o modelo agrícola do caboclo e o do imigrante que adentrou nesta região. Assim, no século XXI vai se presenciar a existência de uma agricultura de roçada e queimada da "capoeira", com rotação de áreas, que vem diminuindo devido à falta de áreas de capoeira, a prática de consórcios (milho-feijão, pepino-melância-melão, melancia-arroz, mandioca-melância e/ou pepino), além de realizarem o plantio direto, isto é, sem revolver o solo, constituindo um sistema típico do caboclo.

Aliado a este modelo, há características dos modelos europeus, como a inserção de forrageiras (aveia) com rotação de culturas, tanto dos cultivos principais (milho-feijão) como dos secundários (mandioca, melancia, dentre outros). Este hibridismo vem a corroborar com o pensamento de Leo Waibel (1949) citado por Schneider (2002), quando fala que durante a adaptação dos imigrantes europeus havia modelos agrícolas distintos. No século 
$\mathrm{XXI}$, o sistema agrário da comunidade Linha Criciumal se caracteriza por apresentar atributos de tais modelos, resultando em um sistema agrário híbrido.

Com o pressuposto acima dissertado, e analisando o sistema produtivo local, com base na interpretação das entrevistas, elaborou-se o calendário de cultivos, em que se apresentam informações acerca da época de plantio e colheita dos cultivos principais (feijão e milho e forrageira) e dos cultivos secundários mais importantes (mandioca e abóbora). Percebendo-se que as espécies sucessionais cultivadas nas glebas ocorrem de forma a privilegiar a completude do ciclo do feijão em maior área útil possível, reservando-se parcelas menores para cultivos secundários (figura 3).

Figura 3 - Calendário de cultivos da comunidade Linha Criciumal

\begin{tabular}{|c|c|c|c|c|c|c|c|c|c|c|c|}
\hline Jan & Fev & Mar & Abr & Maio & Jun & Jul & Ago & Set & Out & Nov & Dez \\
\hline \multirow[t]{5}{*}{$\begin{array}{l}\text { Plantic } \\
\text { (Safrii } \\
\text { ha) }\end{array}$} & & & $\begin{array}{c}\text { Colheit } \\
\text { a } \\
\text { (Safrin } \\
\text { ha) }\end{array}$ & & & & & $\begin{array}{l}\text { Plantio } \\
\text { (Águas } \\
\text { ) }\end{array}$ & & & $\begin{array}{c}\text { Colheit } \\
\text { a } \\
\text { (Águas } \\
\text { ) }\end{array}$ \\
\hline & & & $\begin{array}{c}\text { Colheit } \\
\text { a }\end{array}$ & & & & & & Iantio & & \\
\hline & & & & $\begin{array}{c}\text { Semea } \\
\text { d. } \\
\text { ou } \\
\text { Espont }\end{array}$ & & & & & & & \\
\hline & & $\begin{array}{c}\text { Início } \\
\text { da } \\
\text { colheit } \\
\text { a } \\
\end{array}$ & & & & & & Plantio & & & \\
\hline & $\begin{array}{c}\text { Colheit } \\
\text { a }\end{array}$ & & & & & & & Plantio & & & \\
\hline Legen & & Feijãc & & lilho & & geira & Aveia) & ou espor & tânea & & \\
\hline
\end{tabular}

Como se vê, a cultura do feijão é aquela que ocupa o maior período de tempo e o maior espaço físico (verificado in locu) dentro do sistema produtivo local, fazendo convergir grande parte dos recursos (humanos e naturais) no desenvolvimento desta atividade. Mas, ainda se percebem algumas variações desse subsistema produtivo como o cultivo consorciado de milho com feijão, melancia 
com arroz, e outros mais, e a reserva de áreas para o manejo de espécies arbóreas exóticas como o pinus e eucaliptos, além da pecuária mista (corte e leite), que vem ganhando força.

Por outro lado, a elaboração de um itinerário técnico possibilitou a compreensão da relação entre as etapas, as técnicas, os instrumentos e recursos disponibilizados na produção do componente central do sistema de produção: a cultura do feijão. Apresentando-se as seguintes etapas: preparo da terra; plantio; controle do mato; controle fitossanitário; colheita; e armazenamento, resultando na venda do produto (quadro 1), que pode ser ao cerealista ou para uma cooperativa.

Tabela 1 - Descrição do itinerário técnico da cultura do feijão na comunidade rural de Linha Criciumal em Cândido de Abreu - PR \begin{tabular}{|l|l|l|}
\hline ATIVIDADES & DESCRIÇÃO DAS ATIVIDADES \\
\hline
\end{tabular}

1. Preparo da

O itinerário técnico do sistema de cultivo feijão-milhoterra aveia é marcado inicialmente pelo preparo da terra, que consiste em roçada e queima, quando quer se fazer uma nova área de lavoura, mas se a área de lavoura já é a habitual ocorre à aplicação de herbicida para secar a aveia ou as espontâneas que estão nascendo e que irão compor a cobertura do solo. Como praticam o plantio direto, não é revolvido o solo.

2. Plantio Passados 20 a 30 dias da aplicação do herbicida se procede ao plantio, que ocorre em duas épocas: a da safrinha (Jan/Fev) e das águas (Ago/Set). A maioria dos agricultores utiliza os cultivares de feijão Capixaba, lapuru e Argentino. Alguns agricultores pagam para que pessoas de fora da comunidade semeiem com semeadeiras motomecanizadas, em locais das áreas de lavoura que são mais planas, sem o revolvimento do solo, e ao mesmo tempo em que planta - se se colocam adubos simples como a uréia ou formulados como o NPK 4-14-8 (convencionalmente utilizados pelos agricultores). Outros agricultores plantam ainda de forma tradicional com 0 auxílio da plantadeira manual também chamada de "perna de grilo", e sendo que estes não usam adubo.

3. Controle do O controle do "mato" é outra etapa do processo, que "mato" ocorre por meio da aplicação de herbicidas, que são utilizados de 30 a 45 dias após o plantio. Eventualmente se utiliza a enxada para a capina do 


\begin{tabular}{|l|l|}
\hline & "mato" que não morreu com o herbicida. \\
\hline 4. Controle & $\begin{array}{l}\text { O controle fitossanitário é realizado eventualmente } \\
\text { mediante utilização de fungicidas ou inseticidas no } \\
\text { período de } 30 \text { a } 45 \text { dias após o plantio. }\end{array}$ \\
\hline 5. Colheita & $\begin{array}{l}\text { A colheita se inicia em torno de 90 dias após o } \\
\text { plantio, sendo realizada por integrantes da família. } \\
\text { Também ocorre o pagamento à diaristas provindos da } \\
\text { própria comunidade e de comunidades vizinhas, e, } \\
\text { eventualmente, a troca de dias de serviço com } \\
\text { vizinhos. Desde o início até o término da colheita } \\
\text { levam-se aproximadamente 30 dias, dependendo das } \\
\text { condições meteorológicas, número de pessoas e } \\
\text { tamanho da plantação. O feijão é colhido } \\
\text { manualmente e agrupado em feixes que são } \\
\text { amontoados em um determinado local para ser } \\
\text { "batido" pelo tratorista, em seguida ensacado. }\end{array}$ \\
\hline 6.Armazenamento \\
$\qquad \begin{array}{l}\text { O feijão passa pelo processo de secagem ao sol, que } \\
\text { é realizado no terreiro e sobre uma lona. O expurgo } \\
\text { ocorre mediante utilização de um fumigante que é } \\
\text { colocado nas sacas com posterior fechamento destas } \\
\text { para se evitar o ataque por insetos (caruncho) (para } \\
\text { consumo próprio alguns agricultores passam banha } \\
\text { de porco no feijão para conservá-lo). Depois de } \\
\text { tratado o produto é armazenado em paióis até a } \\
\text { venda. }\end{array}$ \\
\hline
\end{tabular}

Por sua vez, o milho também possui grande importância no sistema de cultivo feijao-milho-aveia, pois também proporciona a completude do ciclo do feijão. Normalmente após a colheita do milho o que sobra é a palhada importante para o solo e logo após, no mês de maio é semeada a aveia, que protege o solo e incorpora matéria orgânica ao mesmo e logo após, no mês de setembro, há o plantio de feijão.

O milho contribui, para este sistema de cultivo, num primeiro momento com a incorporação de macronutrientes ao solo, depois pela manutenção dos restos culturais e o incremento de matéria orgânica ao solo, aumentando a atividade biológica. A palhada do milho, além de incrementar nutrientes ao solo, tem a função de protegê-lo dos raios solares, favorecendo a retenção de umidade, contribuindo para a redução de espontâneas, além de proteger contra as gotas de água da chuva, evitando os processos erosivos.

O milho também contribui para o sistema socioeconômico deste processo, pois além de possibilitar alimento ao agricultor e, 
principalmente, aos animais, em caso de sobras é direcionado para a venda, gerando renda extra ao agricultor, que pode usar estes recursos para investir novamente neste mesmo sistema de cultivo.

Além da compreensão do sistema produtivo milho-feijão, o qual se apresenta como o centro do sistema agrário, buscou-se através de um esboço (figura 4) expressar as relações existentes entre os diferentes subsistemas.

\section{Figura 4 - Fluxos de produtos e da fertilidade de um sistema de} produção familiar na comunidade rural Linha Criciumal

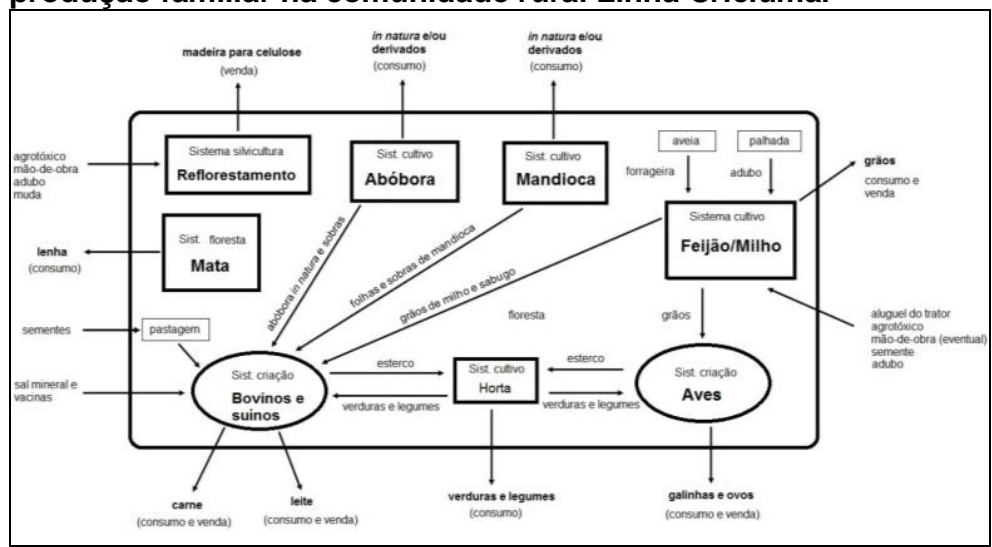

Desta forma, percebe-se que não há uma relação de troca entre o subsistema milho-feijão com os demais subsistemas, o que há é à entrada de insumos e implementos e a saída de matéria-prima para consumo humano e animal e para a venda, além do próprio subsistema se autoalimentar através da palhada da cultura anterior, que se transforma em adubo.

As relações de troca ocorrem entre o subsistema horta com a pecuária (bovina) e aves, sendo que, os dois últimos subsistemas fornecem esterco para a horta e as sobras dos cultivos alimentam as aves, suínos, bovinos, entre outros. Dos subsistemas de criação saem elementos primários como ovo, carne e leite, que podem ser destinados todos para a venda e/ou consumo. Os sistemas de cultivo secundários (sistema abóbora e mandioca) apresentam somente saídas de produtos primários destinados ao consumo humano e 
animal. Já o subsistema mata, apresenta somente saída como a lenha para o consumo. Por sua vez o subsistema reflorestamento, apresenta como entradas as mudas o adubo, mão de obra e agrotóxicos e as saídas se referem ao consumo (pequena escala) e venda de madeira.

O emprego de equipamentos tradicionais aliado a técnicas agrícolas do imigrante e do caboclo, uso de insumos e implementos modernos e inserção de novos subsistemas demonstra que, o sistema agrário local está em permanente processo de transformação. Assim, este híbrido é um produto da ação humana ao longo do tempo, submetida a numerosos fatores de ordem natural, social, e econômica.

\section{CONSIDERAÇÕES FINAIS}

A colonização da região do Paraná Tradicional mostrou que esta região teve sua formação vinculada a latifúndios (fazendas de criação de gado), que somente exploravam os recursos locais sem repô-los, mas também às propriedades familiares de caboclos e imigrantes que mantinham uma relação de equilíbrio com a FOM.

Tais imigrantes europeus foram trazidos com o intuito de alterar os hábitos dos moradores locais, começando pela atividade agrícola, contudo, o contato entre a cultura cabocla e do imigrante, proporcionou novos elementos sociais ao sistema agrário em formação. A partir deste contato há o surgimento de uma lógica produtiva camponesa, responsável pela existência dos atuais sistemas agrários desta região.

Outro agravante que provocou ainda mais mudanças no modo de vida desta sociedade foi à modernização da agricultura. De modo que, em 2013 se observa paisagens produtivas diferentes daquelas de 40 anos atrás, nas quais se presenciavam relações sociais mais equânimes com base em uma organização social mais coesa, onde havia uma maior dependência às limitações do meio físico.

Assim, pode-se constatar que na comunidade rural Linha Criciumal, a qual teve sua história de formação ligada à imigração europeia do início do século XX, no século XXI, desenvolve-se um sistema agrário hibrido, pois da mesma forma como se pratica a roçada e queimada, praticas inerentes ao caboclo, também se 
realizam rotações de cultuas e inserção de forrageiras, práticas típicas do imigrante europeu, além da existência de elementos inerentes a modernização da agricultura.

A análise do sistema agrário local mostrou que, apesar da inserção de novos componentes como agrotóxicos, equipamentos modernos, inserção de outros subsistemas produtivos (bovinocultura e reflorestamento), ainda se mantém muitas práticas tradicionais, como o plantio do feijão e utilização de equipamentos tradicionais (enxada, foice, machado, e outros). Além de que, certas praticas sociais (rodas de chimarrão, partidas de truco, festas, trocas de dias, dentre outras) ainda se mantém, conferindo certa particularidade ao sistema agrário local.

A elaboração de itinerário técnico, calendário de cultivos e fluxos de produtos e fertilidade aponta que na comunidade de Linha Criciumal existe uma agricultura de caráter familiar, cujo componente central do sistema de produção é a cultura do feijão, para o qual converge grande parte dos recursos (humanos e naturais). Já de outro lado, percebe-se que há uma alta integração entre os subsistemas produtivos.

Analisando-se a região Paraná Tradicional e buscando-se compreender o sistema agrário da comunidade Linha Criciumal, evidencia-se que, a relação dos grupos humanos com o ecossistema natural foi mais equilibrada no passado do que é nos dias autuais, pois, no século XXI se tem a diminuição da dependência em relação ao meio físico.

O ecossistema em áreas rurais, agora, passa a ser compreendido como um agroecossistema, um ecossistema controlado pelos agricultores e suas práticas agrícolas. Este ecossistema agrícola possibilita, em certas ocasiões, o uso mais intenso de práticas agrícolas modernas, já em outras predominam práticas tradicionais, apresentando-se níveis variáveis de controle do meio natural. Isto é atestado em relação aos ideótipos agrícolas híbridos, pois, há níveis variados de hibridismo, sendo que os agricultores adeptos destes modelos não apresentam um grande controle sobre o meio físico, contudo, também não são totalmente dependentes deste. 


\section{REFERÊNCIAS BIBLIOGRÁFICAS}

ALBUQUERQUE, U. P.; LUCENA, R. F. P.; CUNHA, L. V. F. C. Métodos e técnicas na pesquisa etnobiológica e etnoecológica (Coleção Estudos e avanços). 1르. ed. Recife: NUPEEA, 2010.

BALHANA, A. P. Política Imigratória do Paraná. Revista Paranaense de Desenvolvimento, n. 87, p.39-50, 1969. Acessado em 1/11/2012. Disponível em: http://www.ipardes.pr.gov.br/ojs/index.php/revistaparanaense/article/v iew/339/292.

CAPORAL, F. R.; COSTABEBER, J. A. A. E. Enfoque científico e estratégico. Revista Agroecol. e Desenv. Rur. Sustent., v.3, n.2, p.13-16, 2002.

COELHO-DE-SOUZA, G. Modernização da agricultura e 0 agravamento da insegurança alimentar no Brasil: o papel das populações locais e sua agrobiodiversidade. In: SILVA, V. A.; ALMEIDA, A. L. S.; ALBUQUERQUE, U. P. Etnobiologia e Etnoecologia: pessoas e natureza na América Latina. Recife: NUPEEA, 2010.

DOMINGUES, A. A. G. Estrutura sócio-econômica e mobilidade geográfica: Melgaço na segunda metade do séc. XIX. Revista da Faculdade de Letras-Geografia, v. 1, n. 1, p.113-177, 1986.

FAGUNDES, A. V. W.; KREVORUCZKA, B. L.; SCHWIDERKE, D. K.; ARAUJO, D. R.; JASINSKI, F. R. G.; PORTO, J. M.; LIMA JÚNIOR, M. S.; GAMA NETTO, N; PARRILI, T.; BLENSKI, V. "Revolução Verde, Agricultura e Capitalismo: o livro cinza do pacote tecnológico do agronegócio". Curitiba: Editora UFPR, 2010.

FLORIANI, N.; FLORIANI, D. Saber ambiental complexo: aportes cognitivos ao pensamento agroecológico. Rev. Bras. de Agroecologia, v. 5, n. 1, p.3-23. 2010. Acessado em 20/08/2012. Disponível em: http://www.abaagroecologia.org.br/revistas/index.php/rbagroecologia/article/viewFile 19529/6624. 
GARCIA FILHO, D. P. Análise e diagnóstico de sistemas agrários - Guia metodológico. Brasília: INCRA/FAO, 1999.

GOMES, R. A. De sitiantes a irrigantes: construção identitária, conversão e projetos de vida. In: GODOI, E. P.; MENEZES, M. A.; MARIN, R. A. Diversidade do campesinato: expressões e categorias. 2 ed. Estratégias de reprodução social. São Paulo: Editora da Unesp, 2009.

HAURESKO, C.; MOTECA, G. A pequena propriedade agrária no Paraná Tradicional: origem, localização e caracterização. In: SIMPÓSIO DE PÓS- GRADUAÇÃO EM GEOGRAFIA DO ESTADO DE SÃO PAULO, 1., 2008, Rio Claro, SP. Anais... Rio Claro: Unesp, 2008. p. 1076-1093. Acessado em: 26/10/ 2012. Disponível em: http://www.rc.unesp.br/igce/simpgeo/1076-1093cecilia.pdf.

INSTITUTO PARANAENSE DE DESENVOLVIMENTO ECONÔMICO E SOCIAL. Diagnóstico socioeconômico do Território Paraná Centro. $1^{\underline{a}}$ fase: caracterização global. Curitiba: IPARDES, 2007.

MACHADO, B. P. Contribuição ao estudo da história agrária do Paraná I: formação da estrutura agrária tradicional dos Campos Gerais. In: SIMPỎSIO DOS PROFESSORES UNIVERSITÁRIOS DE HISTÓRIA, 2., 1962, Curitiba. Anais... Curitiba: Faculdade de Filosofia da Universidade do Paraná, 1963. p. 155. Acessado em 26/10/2012. Disponível em: http://anpuh.org/anais/wpcontent/uploads/mp/pdf/ANPUH.S02.06.pdf.

MAZOYER, M.; ROUDART, L. História das agriculturas no mundo: do neolítico à crise contemporânea. São Paulo: UNESP, 2010.

MERTZ, M. A agricultura familiar no Rio Grande do Sul um sistema agrário colonial. Ensaios FEE, v. 25, n. 1, p.277-298, 2004. Acessado em 15/06/2011. Disponível em: http://revistas.fee.tche.br/index.php/ensaios/article/view/2060/2442.

PADIS, P. C. Formação de uma economia periférica: o caso do Paraná. São Paulo: Hucitec, 1981. 
PAULINO, E. T. Terra e vida: a geografia dos camponeses no Norte do Paraná. 2003. 430f. Tese (Doutorado em Geografia) Universidade Estadual Paulista Júlio de Mesquita Filho.

SANCHES, F.; MACHADO, L. R. M. Segregação espacial e impactos socioambientais: possíveis manifestações da degradação em novas paisagens urbanas. Revista Brasileira de Gestão e Desenvolvimento Regional, v. 5, n. 3, p.29-46, 2009. Acessado em 27/09/2012. Disponível em: http://www.rbgdr.net/0302009/artigo2.pdf.

SANTOS, M. Por uma outra globalização: do pensamento único à consciência universal. 6. ed. Rio de Janeiro: Record, 2001.

SANTOS, M. A Natureza do Espaço: técnica e tempo, razão e emoção. $4^{a}$ ed. 2. reimpr. São Paulo: Editora da Universidade de São Paulo, 2006.

SAUER, C. O. A morfologia da Paisagem. In: CORREA, R. L.; ROSENDAHL, Z. Paisagem, tempo e cultura. $2^{\underline{a}}$ ed. Rio de Janeiro: EdUERJ, 1998.

SCHNEIDER, S. A atualidade da contribuição de Leo Waibel ao estudo da agricultura familiar. Boletim Gaúcho de Geografia, v. 28, n. 1, p.25-41, 2002. Acessado em 15/10/2012. Disponível em: http://seer.ufrgs.br/index.php/bgg/article/view/39932/26261 .

SERRA, E. Os primeiros processos de ocupação da terra e a organização pioneira do espaço agrário no Paraná. Boletim de Geografia, v. 10, n. 1, p.61-93, 1992. Acessado em: 25/10/2012. Disponível em:

http://periodicos.uem.br/ojs/index.php/BolGeogr/article/view/12893/73 60.

TEIXEIRA, J. C. Modernização da agricultura no Brasil: impactos econômicos, sociais e ambientais. Revista Eletrônica da Associação dos Geógrafos Brasileiros, v. 2, n. 2, p.21-42, 2005. Acessado em: 15/10/2012. Disponível em: http://www.ceul.ufms.br/revista-geo/jodenir.pdf. 
VALVERDE O. Sistema de roças: agricultura nômade ou itinerante. Revista Portuguesa de Geografia, v. 3, n. 6, p.225-239, 1968. Acessado em: 25/10/2012. Disponível em: http://www.ceg.ul.pt/finisterra/numeros/1968-06/06_07.pdf.

VENTURI, L. A. B. Ensaios geográficos. São Paulo: Humanitas, 2008.

VERDEJO, M. E. Ministério do Desenvolvimento Agrário. Secretaria da Agricultura Familiar. Diagnóstico Rural Participativo. Brasília, 2006.

WACHOWICZ, R. C. História do Paraná. Curitiba: Gráfica Vicentina Ltda., 1995.

WOORTMANN, E. F. O saber camponês: práticas ecológicas tradicionais e inovações. In: GODOI, E. P.; MENEZES, M. A.; MARIN, R. A. Diversidade do campesinato: expressões e categorias. $2^{\underline{a}}$ ed. São Paulo: Editora da Unesp, 2009. 